\title{
Disclosure Causes of Students Error in Resolving Discrete Mathematics Problems Based on NEA as A Means of Enhancing Creativity
}

\author{
Iwan Junaedi ${ }^{1, *}$, Amin Suyitno ${ }^{1}$, Endang Sugiharti ${ }^{2} \&$ Chin Kin Eng ${ }^{3}$ \\ ${ }^{1}$ Mathematics Department, Semarang State University, Semarang, Indonesia \\ ${ }^{2}$ Computer Science Department, Semarang State University, Semarang, Indonesia \\ ${ }^{3}$ Faculty of Psychology And Education, Universiti Malaysia Sabah, Kota Kinabalu, Malaysia \\ *Correspondence: Mathematics Department, Semarang State University, Semarang, \\ Indonesia. E-mail: iwanjunmat@gmail.com
}

Received: October 22, 2015 Accepted: November 23, 2015 Published: December 18, 2015

doi:10.5296/ije.v7i4.8462 URL: http://dx.doi.org/10.5296/ije.v7i4.8462

\begin{abstract}
This article is based on research cooperation of Foreign Affairs in the first year, which was carried out between the team of lecturers from the Department of Mathematics Education Unnes (Indonesia) with Dr. Chin Kin Eng, a lecture of Mathematics Education from Universiti Malaysia Sabah. The main objective of this research in the first year is to uncover the cause of the students error in resolving Discrete Mathematics by Newman Errors Analysis (NEA). The Results of this research will be used as the basis for the subsequent research that reveal the mathematical creativity of the students. Outcomes of this research is the publication of research results in the International Journal and seminar at the international level. As a qualitative research, data collection through an analysis of the results of tests, questionnaires, observations, and interviews. Data analysis are data reduction, exposure of data, synthesising the data, triangulation, and the inference/verification. According to research, known that students errors in resolving discrete mathematics caused by: (1) the student did not know the meaning of a symbol or an existing term in the problem (Reading Errors), (2) the student did not understand the meaning of the problem, namely the student fails to write what is known and what is being asked (Comprehension Errors), (3) students forgot a formula that will be used or strategy/procedure what to do (Transformation Errors), (4) students could not make the problem-solving algorithms in sequence and correctly (Process Skills Errors), (5) the student could not answer according to the question (Encoding Errors), and (6) the student could not translate well, especially about which was written in English (Language Errors). Errors caused by carelessness students (Careless Errors) was not found. After giving Learning Therapy for the provision to resolve a problem through the algorithm and the correct sequence, the causes of the error of some students could be minimized, so that the number of students who were experiencing errors could also be reduced. Results of this research became the basis for continued research in the second year, which will be revealed and developed the mathematical creativity of students with prepare advanced research instruments.
\end{abstract}

Keywords: Newman Error Analysis (NEA), Discrete Mathematics, Creativity 


\section{Introduction}

\subsection{Background}

Society of Sabah Malaysia and Indonesia, especially in Semarang, often referred to as a nation allied but different countries. Therefore, research cooperation will be carried out between the team of lecturers from the Study Program of Mathematics Education, Semarang State University (Indonesia) with Dr. Chin Kin Eng, a lecture of Mathematics Education from Universiti Malaysia Sabah. According to Mann (2006), the essence of mathematics is the mathematical creativity. Furthermore, Perkin (2006) and Sambo (2014) emphasizes that the creative power of mathematics is very important and needs to be developed at the school. In the first year of research, before a model disclosure and improvement of mathematical creativity is developed, students need to be trained in advance in order to avoid mistakes in the work on the problems and avoid optimally causes the students to see mistakes. Disclosure fault location and cause of the error based on the Newman Error Analysis (NEA).

If the findings of NEA can be detected the fault location and cause of students errors in doing math, then the students can be given Learning Therapy, followed by the preparation of the instrument by researchers to uncover the creativity of mathematics to students in both countries. Referring to Wang (2011) and Mann (2005), instruments for the 2nd year research that will be tested include flexibility, fluency, originality, and elaboration.

\subsection{Problems}

Based on the background above, the problems of this cooperation research with foreign countries in the first year as follows.

1) By using Newman Error Analysis (NEA), where are the errors and the causes of the Mathematics Education students error in doing mathematics problems?

2) What are the actions of Learning Therapy to minimize students errors which have expressed through the NEA?

\subsection{Main Objectives of The Research}

The main objective of the research (year 1 and year 2), to find a development model of increasing students mathematical creativity of Mathematics Education Department, Semarang State University and Universiti Malaysia Sabah based on the findings of the NEA, by finding points of similarity and the difference of the two allied nations but different countries.

\subsection{Target Outcomes}

The target outcomes of this research are the publication of the results of this research in the International Journal and also seminar at international level. Designed, the research was conducted in two years. The first year, will reveal the location and cause of why the students of Mathematics Education in both countries made a mistake, using Newman Error Analysis (NEA) as a tool. Furthermore, continued with action Learning Therapy. After that, proceed with the preparation of the draft instrument to uncover and develop the mathematics creativity of students in both countries. 


\section{Review of Literature}

\subsection{Newman Error Analysis (NEA)}

Newman Error Analysis (NEA) is often called the procedure Newman. NEA is widely used and applied in different countries and used as a tool to determine the cause of the various types of errors made student or students in doing math problems.

In solving math problems, especially in the form of the description and nature of literacy, the error must be avoided as much as possible. The ability to do math with careful steps, right, and detailed often referred to do math through Mathematical Literacy. Hofer and Beckmann (2009) writes that the mathematical literacy is an individual's capacity to identify and understand the role that mathematics plays in the world, to the make well-founded judgments and to use and engage with mathematics in ways that meet the needs of that individual's life as a constructive, concerned, and reflective citizen. To be able to work on the problems, Dahlin, B \& Watkins, D (2000) asserts that the understanding is more likely to lead to high quality outcomes than memorizing. Math-related learning, faculty should also encourage students to try to do math carefully, including through the inquiry/investigation carefully. Wachira, Pourdavood, and Skitzki (2013) in a journal wrote that mathematics instruction should provide students opportunities to engage in mathematical inquiry and meaning making through discourse, and teachers should encourage this process by remaining flexible and responsive to students' response and feedback.

In mathematics learning, studying in depth and avoid the mistakes indispensable. On the other hand, repetition of material for students who are relatively weak is also still needed. Although, Marton, F \& Saljo, R (1976) writes that in mathematics education, there has been tension between deep learning and repetitive learning. Further reaffirmed that in western culture often repetitive learning is positioned as the opposite of deep learning and understanding. In the study of mathematics, the student or students need to understand the material. Not only memorized, so that students avoid mistakes. Lie, S (2006) also writes that: Western educators emphasise the need for students to construct a conceptual understanding of mathematical symbols and rules before they practice model the rules. Watkins, D \& Biggs, JB (2001) also did not agree that the learning of mathematics dominated by memorization activities. They found: One aspect of the criticism is that rote learning is known to lead to poor learning outcomes.

Searching or tracing on the cause of the students error in solving math problems, especially in the form of a description which will be revealed through qualitative research. Study is based on analysis of the sequence error using the NEA. NEA as a tool to find the cause of the fault types of students in working on the problem, are worldwide regarded as already implemented in various parts of the world such as India, Malaysia, Thailand, Australia, and so on. The following will discuss about the NEA as a tool in finding the cause of the error or the students in working on math problems.

From the writings of White (2005), Singh, Rahman, and Hoon (2012), Jha (2012), Prakitipong and Nakamura (2006), it can be concluded that the order of procedure in determining the cause of the error Newman student in solving math problems is as follows. 
1) Error type $R$, if the cause of students can not read because, in a sense can not understand the meaning of symbols, terms, or words used in the problem.

2) Error type $C$, if the cause of students do not understand the meaning of the problem that characterized by students can not write what is known and what is being asked by the problem.

3) Error type $T$, if the cause of students fails to specify what formula is used or failed to find strategies or procedures to be used.

4) Error type P, occurs if the cause of students fails to work or student is not in accordance with the algorithm correctly.

5) Error type E, if the cause of students not able to answer according to what is being asked by the problem.

\subsection{Mathematical Creativity}

\subsubsection{Mathematical Creativity and Its Developments}

The specific objective of this research in the first year, to uncover the cause of students error in solving Discrete Mathematics problems by Newman Errors Analysis (NEA), which will be used as a means toward continued research to uncover the mathematical creativity of students. Disclosure of the mathematical creativity of students will be conducted to the second year research. The creativity of mathematics or mathematical creative thinking abilities, an act of thinking that generates creative ideas or new ways of thinking, original, independent, and imaginative in mathematics. Creativity can be seen as a mental process. This creativity refers to the ability to think more one step forward and is a product of ideas than to most others.

In line with the above article, then according to Naiman (2006), Creativity is the act of turning new and imaginative ideas into reality. Creativity involves two processes: thinking, and then producing. Innovation is the production or implementation of an idea. If you have ideas, but do not act on them, you are imaginative but not creative. So, Naiman illustrate that creativity as an act of turning imaginative ideas and a new character into reality. Creativity involves two processes of thought and then produce. Innovation is the result or the implementation of an idea. If someone has ideas but not through processes that then someone was saying imaginative but not creative people.

Hasan (1997) wrote that the word "kreativitas" (in Indonesia) comes from the word of the West "creativity" which means efforts to create or creativity. Word of creativity also comes from the Latin word creare which means "to make". However, according to Torrance (1988) is very difficult or impossible to provide a definition that is really appropriate. Cause, because the characteristics of creativity itself also infinitive and involve all the senses possessed by humans, including the senses of sight, hearing, smell, taste, and feeling. Torrance (1988) also added that it is very difficult to express the definition of creativity in the form of words. Apart from that, Isaksen (1987) also support the notion Torrance above, by asserting that very difficult to give a precise definition of creativity which is concerned with the nature of creativity itself. 
Isaksen (1987) added another, that no one any discipline can assume that only the disciplines that are entitled to examine the power of creativity. Morgan \& Forster (1999) explains that in the field of education, the educators in their efforts to know for sure that creative students need to understand what is meant by the power of creativity. According to Goh (1993), understanding of the concept of creativity is very important for teachers because through understanding, will be available one pattern to guide teachers in designing and implementing typical exercise program to improve students' creativity.

Cropley (2001) argued that overall the experts in the field of creativity agree that creativity has three main elements, namely: (1) Authenticity (something the product, action or creative ideas should aberrant). (2) Achievement (achieve desired goals). (3) Ethical (the term creative power is not usually used to describe acts like an arrogant selfish, destructive behavior, and the like). In conclusion, understanding the concept of creativity is in fact, very important especially for prospective teachers or teachers whose role fostering creativity of students in class.

This creativity, needs to be cultivated first among students of teacher candidate. Mathematical creativity is indispensable when it later if teacher candidate after as a teacher wants to establish a mathematical creativity of the students, especially when students need to solve the problems of mathematical challenge.

So, the students creativity can be formed, then there are seven attitude of lecturer who should be: (1) willing to listen to opinions, questions, or even complaint of students; (2) willing to respect the opinion of the students, even if it is incorrect; (3) foster and develop self-confidence of students; (4) is ready and willing to provide a challenge to the students; (5) encourage students to dare to express ideas; (6) did not dare to create a sense of fear among the students themselves. The attitudes above are required by the students, because if students are wrong, for example, the student would not dare to try new things, which means students' creative power is not formed. Increased creativity of the students need to be analyzed and escorted in order to avoid a failure in the process of enhancing the creativity of mathematics.

Eric Louis Mann was a lecturer of Mathematics Education at the University of Connecticut who wrote in a journal on mathematical problems that are expected to form the Mathematical Creativity, which are the open ended problems. According to Takahashi (2006), the open ended problem is a problem that has many solutions or solving strategies. The use of open questions give the student or the student resource rich experience in interpreting the problem and allow students to produce different solutions.

According to Mann (2005) and Wang (2011), indicators of student grows their the mathematical creativity are (1) student flexible (flexibility) to solve the problems that have a lot of strategies/different way of its solution, (2) student fluent (fluently), which is indicated by the ability to produce the right answers that different, (3) student has the original work (originality), the solution is the work her/himself, and (4) student has a conscientious, right, and detail (elaboration) in resolving the problem. 


\section{Research Methods}

\subsection{Subject and Location of Research}

Subjects of this research, chosen 5 to 10 students of Mathematics Education from the State University of Semarang, and 5 to 10 students of Mathematics Education from Universiti Malaysia Sabah. Location of research: (1) In Mathematics Education Study Program, Department of Mathematics of Semarang State University, Gunungpati, Semarang, Indonesia and (2) in Mathematics Department, Faculty of Psychology and Education - Universiti Malaysia Sabah, UMS, 88400 Kinabalu.

\subsection{Collection and Analysis of Data}

As a qualitative research, the collection of data through an analysis of the test results, questionnaires, observations, and interviews. Data analysis are data reduction, exposure of data, synthesising the data and triangulation, and than inference/verification.

\subsection{Indicators of Accomplishment}

The research results indicators are as follows.

1) Can be revealed the location and cause of why the students of Mathematics Education of Semarang State University and Universiti Malaysia Sabah made a mistake, using Newman Error Analysis (NEA) as its tool and forwarded to the Learning Therapy action.

2) There are operational actions namely Learning Therapy as a follow-up of the indicator number 1 .

3) Composed of the instrument draft to reveal the mathematical creativity of students in both countries based on components: flexibility, fluency, originality, and elaboration.

4) Publication of the first year of research products in the International Journal and the International Seminar.

\section{Results of Research}

\subsection{Cause of Error According to Newman Errors Analysis (NEA)}

After lecturer gives the material, then the students were given about the subjective problems. Furthermore, after corrected by the lecturer, the table of initially findings are as follows.

Table 1. Acquisition Scores

\begin{tabular}{ll}
\hline Score & The number of students \\
\hline $86-100$ & 3 \\
$81-85$ & 10 \\
$71-80$ & 12 \\
$61-70$ & 7 \\
$0-60$ & 0 \\
The sum of students & 32 \\
\hline
\end{tabular}


Table 2. Type of Error and the Number of Students

\begin{tabular}{ll}
\hline Type of Error & The number of students \\
\hline Type R or Reading Errors & 1 \\
Type C or Comprehension Errors & 2 \\
Type T or Transformation Errors & 3 \\
Type P or Process Skills Errors & 12 \\
Type E or Encoding Errors & 9 \\
Type L or Language Errors & 2 \\
Type X or Careless Errors & 0 \\
No Errors & 3 \\
The sum of students & 32 \\
\hline
\end{tabular}

While the cause of the students error in solving the problems of Discrete Mathematics by Newman Errors Analysis (NEA) had findings/results as follows:

1) Errors because students did not know the meaning of a symbol or a term that is in the problem (Type R or Reading Errors).

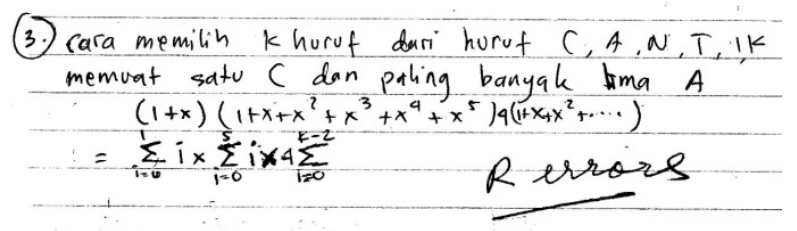

Based on the result of the analysis of student work and interviews it was revealed that the cause of the error because the student did not know the meaning of a symbol or a term that is in the problem.

2) Errors because students did not understand the meaning of the problem, the students failed to write down what is known and what is being asked (Type $\mathrm{C}$ or Comprehension Errors).

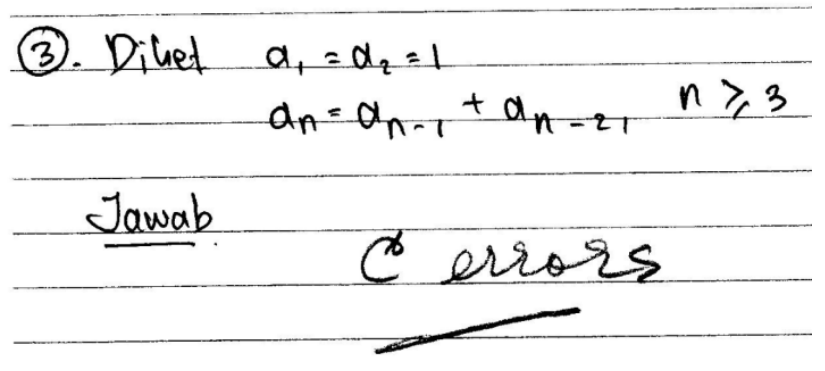

Based on the result of the analysis of student work and interviews it was revealed that the cause of the error because the students did not understand the meaning that it could not write about what is known and what is being asked correctly.

3) Error because students forgot a formula that will be used or strategy/procedure what to do (Type T or Transformation Errors). 
2. Divet: $a_{0}=0, a_{1}=1, a_{2}=2, a_{3}=3$; $a_{n}+2 a_{n-2}+a_{n-4}=0, n \geq, 4$

Ditanya : Relasi reluersif

Answer: $a_{n}=x^{n}$

$a_{n}+2 a_{n-2}+a_{n-4}=0$.

$x^{n}+2 x^{n-2}+x^{n-4}=0$.

$x^{4}+2 x^{2}+1=0$.

\section{Terrors}

4) Error because the students were not able to problem-solving algorithms in sequence, detailed, and correct (Type P or Process Skills Errors).

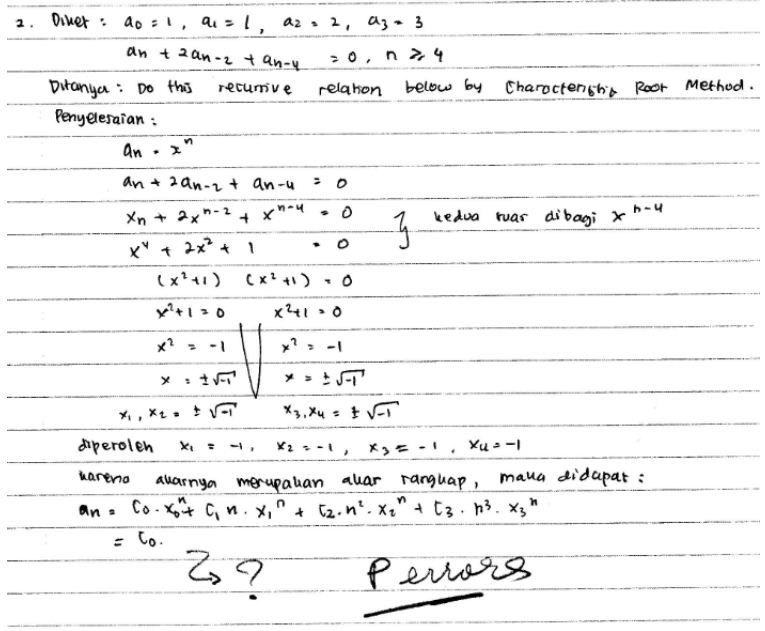

Based on the result of the analysis of student work and interviews it was revealed that the cause of the error because students failed to do the problem-solving algorithms in sequence, detailed, and true.

5) Error because the student could not answer the question because according to (type E or Encoding Errors).

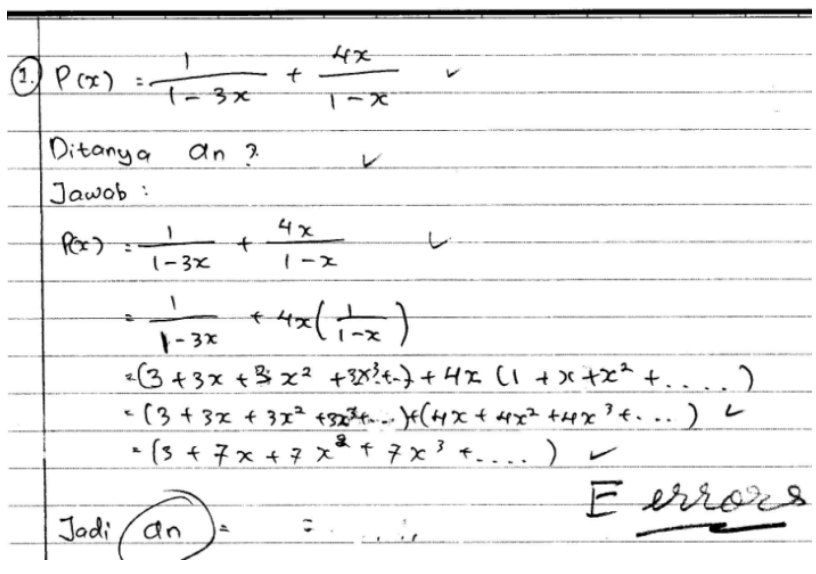

Based on the result of the analysis of student work and interviews it was revealed that the cause of the error because students failed to answer the question in accordance the problem.

6) There are errors that occur, because the students did not successfully translate well, especially the question written in English (Type L or Language Errors). 
The problem was taken from Clark and Holton (1991), which was given to students were as follows. A high school wishes to timetable for examinations in nine different subjects. Of course if there is a pupil doing two of these subject their examinations must be held in different time slots. The table below shows (by crosses) which pairs of subject, labelled A to I, have at least one pupil in common. The school wishes to find the minimum number of time slots necessary and how to allocate subjects to times accordingly. Interpretting this problem as a graph colouring problem, find the minimum number of time slots needed and a suitable time allocation of the subjects.

\begin{tabular}{|c|c|c|c|c|c|c|c|c|c|}
\hline & A & B & $\mathrm{C}$ & $\mathrm{D}$ & $\mathrm{E}$ & $\mathrm{F}$ & $\mathrm{G}$ & $\mathrm{H}$ & I \\
\hline A & & $X$ & $\mathrm{X}$ & $X$ & & & & & \\
\hline B & $X$ & & & $X$ & & & & & \\
\hline $\mathrm{C}$ & $X$ & & & & $X$ & & & $X$ & $X$ \\
\hline D & $X$ & $X$ & & & $X$ & $X$ & & & \\
\hline $\mathrm{E}$ & & & $X$ & $X$ & & $X$ & $X$ & & \\
\hline $\mathrm{F}$ & & & & $X$ & $X$ & & $X$ & & \\
\hline $\mathrm{G}$ & & & & & $X$ & $X$ & & $X$ & \\
\hline $\mathrm{H}$ & & & $X$ & & & & $X$ & & $X$ \\
\hline I & & & $X$ & & & & & $\mathrm{X}$ & \\
\hline
\end{tabular}

There were students who did not give the solution of the problem above.

7) The error due to carelessness (Careless Errors), not found.

\subsection{Giving Learning Therapy}

Learning Therapy done by providing examples of various problem-solving of Discrete Mathematics in the following manner. (1) Studying material prerequisite underlying of the problem solution (to avoid the cause of the error type R). (2) Practicing understand the problem by writing what is known and what is being asked correctly (to avoid the cause of the error type C). (3) Practicing to write a formula or a strategy of solution so that further work has a clear and correct direction (to avoid the causes of errors of type T). (4) Solving the problems based on formulas and strategies that have been carefully selected, detailed, and completely (to avoid the cause of the error type P). (5) To train the students to recheck of their work in answer the question in accordance with the question of the problem (to avoid the cause of the error type E).

Moreover, in order that students skilled in working on which is written in English, then 
students have a lot to learn English. After the Learning Therapy is given for the provision of how to solve a problem that is correct as described above, then the cause of the error experienced by some students above can be minimized, so that the number of students who are experiencing errors can also be reduced.

These results as significant input and a means to continue the research in the second year, which will reveal and develop the creativity of students by arranging the advanced research instruments that reveal the mathematical creativity.

\subsection{Follow-Up}

Assuming that a student has been unable to escape and reduce the various factors that cause errors in working on Discrete Mathematics, the follow-up of the results of this research are as follows.

1) Make the draft of instrument to reveal the mathematical creativity of students in both countries in the components of flexibility, fluency, originality, and elaboration.

2) Through qualitative research, re-expressing the growth and increase of the creativity of mathematics to students in both countries, which include: preparation of the instrument, the use of instrument, preparation of the manual, device evaluation and analyze.

3) Publication of the second year of research products in the International Journal and the International Seminar.

\section{References}

Borg \& Gall. (1979). Educational Research: an introduction. New York: Longman, Inc.

Clark, John \& Holton, Derek Allan. (1991). A First Look At Graph Theory. Singapore: World Scientific Publishing Co. Pte. Ltd, 198.

Cropley, A.J. (2001). Creativity \& cognition: producing effective novelty. Roeper Review, 21, 253-263.

Dahlin, B., \& Watkins, D. (2000). The role of repetition in the pocesses of memorizing and understanding: A comparison of the views of German and Chinese secondary school students in Hong Kong. British Journal of Educational Psychology, 70, 65-84. http://dx.doi.org/10.1348/000709900157976

Goh, C. T. (1997). Shaping our future: thinking schools \& a learning nation. Prime Ministers's speech at the opening of the 7 International Conference. On Thinking (2 June), Speeches, 21(3) 12-20.

Hasan, Langgulung. (1997). Kreativiti \& Pendidikan: Suatu Kajian Psikologi \& Falsafah. Kuala Lumpur: Dewan Bahasa \& Pustaka.

Hofer dan Beckmann. (2009). Supporting mathematical literacy: examples from a cross-curricular project. ZDM Mathematics Education Journal, 41, 223-230. 
http://dx.doi.org/10.1007/s11858-008-0117-9

Isaksen, S. G. (1987). Frontiers of Creativity Research Beyond the Basic. New York: Bearly Limited.

Jha, Shio Kumar. (2012). Mathematics Performance of Primary School Students in Assam (India): An Analysis Using Newman Procedure. International Journal of Computer Applications in Engineering Sciences [VOL II, ISSUE I, MARCH 2012]. Retrieved from http://www.caesjournals.org/uploads/IJCAES-CSE-2011-191.pdf

Lie, S. (2006). Mathematics education in diferent cultural traditions: A comparative study of East Asia and the West. New York: Springer.

Mann, Eric L. (2005). Mathematical Creativity and School Mathematics: Indicators of Mathematical Creativity in Middle School Students. Dissertation of University of $\begin{array}{llllll}\text { Connectitut. } & \text { Retrieved } & 15 & \text { November } & 2014 & \text { from }\end{array}$ http://www.gifted.uconn.edu/siegle/Dissertations/EricMann.pdf

Mann, Eric L. (2006). Creativity : The Essence of Mathematics. Journal for the Education of the Gifted, 30(2), 236-260. http://dx.doi.org/10.4219/jeg-2006-264

Marton, F., \& Saljo, R. (1976). The experiences of learning. Edinburg, UK: Scottish Academy Press.

Morgan, S., \& Forster, J. (1999). Creativity in the classroom. Gifted Education International, 14(1), 29-43. http://dx.doi.org/10.1177/026142949901400105

Naiman, Linda. (2006). What is Creativity? Retrieved 23 November 2014 from http://www.creativityatwork.com/ articlesContent/what is.htm

Perkins, C., \& Murphy, E. (2006). Identifying and Measuring Individual Engagement in Critical Thinking in Online Discussions: An exploratory case study. Educational Technology \& Society, 9(1), 298-307.

Prakitipong, Natcha \& Nakamura, Satoshi. (2006). Analysis of Mathematics Performance of Grade Five Students in Thailand Using Newman Procedure. CICE Hiroshima University. Journal of International Cooperation in Education, 9(1), 111.

Sambo, Sani \& Ibrahim, Maruf O. (2014). Mathematical Creative Development Among Children: A Precusor for Counsellors and Mathematics Teachers. European Scientific Journal, 8(24), 164-169.

Singh, Parmjit, Rahman, Arba Abdul, \& Hoon, Teoh Sian. (2010). The Newman Procedure for Analyzing Primary Four Pupils Errors on Written Mathematical Tasks:A Malaysian Perspective: International Conference on Mathematics Education Research 2010 (ICMER 2010).

Takahashi, A. (2006). Communication as Process for Students to Learn Mathematical. Retrieved from http://www.criced.tsukuba.ac.jp/math/apec/apec2008/papers/PDF/14.Akihiko_Takahashi 
_USA.pdf

Torrance, E.P. (1988). The nature of creativity as manifest in its testing. In R. J. Sternberg (Ed.), The Nature of Creativity: Contemporary Psychological Perspectives (pp. 43-75). Cambridge University Press.

Wachira P., Pourdavood R., \& dan Skitzki, R. (2013). Mathematics Teacher's Role in Promoting Classroom Discourse. International Journal for Mathematics and Learning. Retrieved 8 June 2013 from http://www.cimt.plymouth.ac.uk/journal

Wang, Amber Yayin. (2011). Contexts of Creative Thinking: A Comparisonon Creative Performance of Student Teachers in Taiwan and the United States. Journal of International and Cross-Cultural Studies, 2(1), 1-14.

Watkins, D., \& Biggs, J.B. (2001). The paradox of the Chinese learner and beyond. Teaching the Chinese learner. Psycological and pedagogical perspectives. Melbourne: ACCER.

White, Allan L. (2005). Active Mathematics In Classrooms Finding Out Why Children Make Mistakes-And Then Doing Something To Help Them. Sidney: University of Western Sydney. Square One, Vol 15, N0 4, December 2005.

\section{Copyright Disclaimer}

Copyright for this article is retained by the author(s), with first publication rights granted to the journal.

This is an open-access article distributed under the terms and conditions of the Creative Commons Attribution license (http://creativecommons.org/licenses/by/3.0/). 